\title{
ALGUNOS CASOS TERATOLOGICOS OBSERVADOS EN LOS ARTROPODOS.
}

\author{
Prof. Francisco Campos R.*
}

1. Caso de tarso hexamero en el Tetracha suturalis Horn. (Coleóptero de la familia Cicindelidæ).

Es esta una espécimen cuyas extremidades son normales á excepción del tarso mesotorácico izquierdo el cual en su tercera articulación parece haber recibido fractura y soldado después. Presenta pues un tarso mesotorácico de 6 artejos lo que hace que la extremidad mesotorácica izquierda sea sensiblemente mas larga que su correspondiente metameral.

Procedencia de esta forma: El Morro.

2. Caso de anomalia elitral en el Mallodon molarium Bat.

(Coleóptero de la familia Prionidæ.)

Consiste este caso teratológico en una hipertrofia del élitro derecho y desvio de la línea de sutura media. Los élitros son normales en su base, y ambas piezas se tocan hasta los dos tercios de su longitud. A partir de este punto el borde interno del élitro derecho se separa de la línea de sutura dejando al descubierto parte de las alas membranosas y la margen externa del mismo élitro se expande notablemente no coincidiendo en su terminación con el extremo del élitro izquierdo el cual conserva en todo perfecta regularidad.

Hab.: Duran.

3. Caso de bifurcacion tibio-femoral en un Calopteron sp. (Coleóptero de la familia Lycidæ.)

Representa esta muestra aberrante un tipo heptápodo. Las patas están normalmente desarrolladas á excepción de la metatorácica izquierda la cual en la región media del femur se bifurca constituyendo desde este punto 2 piezas que se articulan después con 2 tibias perfectamente independientes con sus respectivos tarsos. El insecto en referencia ofrece pues, 7 tibias y casi puede decirse 7 fémures, puesto que la bifurcación comprende también la mayor longitud femoral.

Hab.: Chimbo.

* El suscrito catedrático de Ciencias Naturales del Colegio Nacional Vicente Rocarfuerte de Guayaquil (Ecuador) y miembro de la Entomolog. Soc. of America, presenta por intermedio del Prof. J. M. Aldrich-a esa Honorable Corporación, las signientes observaciones recogidas durante su práctica de Entomologista. 
4. Caso de atrofia tibio-femoral en el Alurnus 4-maculatusé (Coleóptero de la fam. Hispidæ.)

Trátase de un ejemplar $\sigma^{7}$ cuya extremidad mesotorácica derecha ofrece notable anormalidad. El trocanter mesotorácico es normal; femur notablemente reducido á una quinta parte de la longitud natural, tibia fuertemente curva hacia adentro, á modo de $C$ y muy corta (un tercio del tamaño natural); tarso normal. El ejemplar observado por el dorso apenas deja ver el tarso de la extremidad aberrante, quedando ocultas las demás regiones de dicha extremidad, á causa de su reducido tamaño.

Hab.: Baños.

5. Caso de aberración bicaudata en el Centrurus margaritatus (Gerv.)-(Arácnido de la familia Scorpionidæ.)

Constituye un caso teratológico interesantísimo. Un alacrán con 2 colas completamenta distintas, bien desarrolladas, fenómeno considerado por varios autores como fabuloso. E1 ejemplar aludido presenta 2 postabdómenes (colas) independientes é ignalmente. desarrollados, unidos al preabdomen y provistos de sus correspondientes aguijones. Se observa que, cada postabdomen aunque bien desarrollado ofrece sus metámeros algo menos fuertes que en los de un ejemplar normal.

Hab.: Duran.

Localización poco frecuente del Phthirius inguinalis.

El suscrito constata un caso de alojamiento rebelde del parásito arriba indicado, en la base de las pestañas de ambos ojos, en un niño de 5 años, y temporalmente su presencia en el cabello-(Va 1 tubo con alcohol y varios ejemplares). 